Dulmen, A.M. van, Holl, R.A.

Effects of continuing paediatric education in interpersonal communication skills.

European Journal of Pediatrics: 159, 2000, p. p. 489-495

\begin{tabular}{|l|l|}
\hline $\begin{array}{l}\text { Postprint } \\
\text { Version }\end{array}$ & 1.0 \\
\hline Journal website & http://dx.doi.org \\
\hline Pubmed link & $\begin{array}{l}\text { http://www.ncbi.nlm.nih.gov/entrez/query.fcgi? cmd=Retrieve\&db=pubmed\&do } \\
\mathrm{pt=Abstract \& list} \mathrm{uids=10923220 \& query} \mathrm{hl=8 \& itool=pubmed} \mathrm{DocSum}\end{array}$ \\
\hline DOI & $10.1007 / \mathrm{s} 004310051316$ \\
\hline
\end{tabular}

A. M. van Dulmen $(\varangle) \cdot$ R. A. Holl - Netherlands Institute of Primary Health Care (NIVEL), PO Box 1568, 3500 BN Utrecht, The Netherlands - e-mail: S.vandulmen@nivel.nl - Tel.: +31-30-2729703; Fax: +31-30-2729729

ALEXANDRA M. VAN DULMEN $\cdot$ ROBERT A. HOLL

\title{
Effects of continuing paediatric education in interpersonal communication skills
}

\begin{abstract}
Paediatric care places great demands on interpersonal communication skills, especially as regards the handling of psychosocial issues. Recent shifts in paediatric morbidity and increases in patient empowerment furthermore emphasize the need for continuing paediatric education in communication skills. It is, however, debatable, whether after residency paediatric education can influence paediatrician performance. This study evaluated the effects of a 5-day experiential communication training by means of a pretest/post-test control group design. A total of 21 consulting paediatricians (10 experimental, 11 control group paediatricians) videotaped two series of consecutive outpatient encounters. Compared with the untrained control group, trained paediatricians asked more psychosocial questions and looked at the patients and their parents more often. In addition, they gave patients and parents more room to talk. No difference was found in the length of the outpatient visits.

Conclusion Paediatric education after residency influences paediatricians' verbal and nonverbal communication skills positively, especially as regards handling psychosocial issues. On the basis of these findings, it appears worthwhile to encourage continuing paediatric education in interpersonal communication skills.
\end{abstract}

\section{INTRODUCTION}

Training in medicine occurs predominantly in preclinical and residency years. There are, however, several reasons for encouraging continuing paediatric education, especially as regards interpersonal communication skills. Firstly, at least in the Netherlands, established paediatricians have an important role as teachers for students and residents [33]. Consequently, training paediatricians will have a subsequent impact on student performance. Secondly, there appear to be shifts in paediatric morbidity towards more psychosocial and developmental problems [21] which require a broad range of communication skills. Thirdly, communication training was very little in evidence when most consulting paediatricians underwent their own medical education [15]. Recent increases in patient empowerment and autonomy [32], however, place great demands on the physician's communication skills. The American Board of Pediatrics strongly recommends the inclusion of teaching and assessment of communication skills in training programmes [2]. Consulting paediatricians even consider such non-cognitive skills the most critical aspects of good performance [1]. Approaching a child, managing family dynamics and addressing patients' concerns and questions are key elements of paediatric encounters [35]. Therefore, the paediatricians' ability to handle psycho-social issues 
effectively is very important [14]. They can do this verbally by inquiring about feelings and lifestyle and nonverbally by attentively looking at the patients and their parents [4].

Previous research suggests that paediatricians have difficulty in including children in the conversation $[9,18]$. They appear to be able to gather information from the child, but seem to lack the capacity to provide management and diagnostic information. The present paper elaborates on a previous one [9] which stressed the need for more elaborate training courses on communication with children and their parents. Training programmes for primary care physicians and residents have already been shown to be effective in acquiring communication skills [17, 25, 26, 28]. In short, these studies demonstrated training to produce a whole host of skill changes which were linked to the use of more psychosocially directed questions and to better identification of patients' emotional distress.

In developing communication courses the best is to keep track of what pediatricians themselves perceive as relevant topics [1,19]. After all, as a result of their many years' experience they are the obvious persons to determine the importance of different ingredients and the necessary attitudes, skills and efficiency for performing successful encounters. Recently, a group of consulting paediatricians attended such an experiential communication training. The following questions were addressed: 1) how did paediatricians assess the training?; 2) what were, compared with an untrained control group, the effects of the communication training on paediatricians' performance in handling psychosocial issues, in providing information, and in encouraging patients' and parents' conversational contribution?

\section{SUBJECTS AND METHODS}

\section{Communication training}

Two experienced trainers, a psychotherapist and a primary care physician, ran all the meetings of the 5-day communication training held at a conference centre. The training aimed at identifying maladaptive communication skills (e.g. ignoring the presence of the child) and encouraging and acquiring alternative and more effective ways of communicating with children and their parents (e.g. inquiring about how parents cope with their child's condition). This aim was accomplished by assisting paediatricians to acquire patient-centred interviewing skills [16] and handle parents' and children's instrumental and affective needs, by providing information and advice and showing support and understanding, respectively. An important part of this experiential training was dedicated to watching and discussing videotapes of trainees' actual performance during outpatient encounters. These discussions focused on real-life examples of effective and less effective communication behaviours. This gave insight into each paediatrician's characteristic way of communicating and encouraged a learner-centred approach with personal learning objectives, self-awareness, colleagues' constructive feedback and comments, and suggestions for alternatives. In toto, the post-residency training combined: 1) paediatrician education on the significance of communicating affect, of attending to psychosocial issues, and of giving the patient and the parent room to talk; 2) theoretical and practical homework and application of what was learned between sessions; 3) role-playing exercises, for becoming comfortable with alternative communication skills; 4) trainers' and colleagues' feedback of videotaped and role-play interaction style and 5) discussion of paediatricians' own experiences. These training techniques had previously been identified as educational methods of demonstrated effectiveness and feasibility $[11,14,20,22,29,30]$. The training was accredited by the Paediatric Association of the Netherlands. In terms of the aims of the training, trainees were expected to become less verbally dominating and more supportive, to pay more attention to parents' and childrens' thoughts and feelings, as dictated by a patient-centred approach and to look at the parent and the patient more often.

\section{Sample}

A comparison was made between a group of ten paediatricians who participated in the training and a control group of 11 paediatricians who undertook the course later on (a pretest/post-test control group design). Paediatricians were recruited by means of an announcement of the training and accompanying research in the newsletter of the Paediatric Association of the Netherlands. To prevent cross-over of information between conditions, participants in the control group were recruited from general hospitals other than those in the intervention group. Table 1 summarizes paediatrician and patient characteristics for both groups. Apart from the reimbursement system both groups appeared to be 
well-matched. In the Netherlands, a paediatrician is a consulting physician and member of a hospital staff $[7,33]$.

\section{[ TABLE 1 ]}

\section{Assessment of training effects}

Prior to (T0) and 4 months after (T1) completing the training, all participants were asked to videotape a series of consecutive outpatient visits. About 1 week before the appointment with the paediatrician, parents were informed of the nature of the study and were asked to give written consent to allow recording for research purposes. Finally, 608 encounters were videotaped using a fixed unmanned camera (Table 2). Training effects were measured by comparing paediatricians' performance on the videotapes at pre(T0) and post-measurement (T1). The use of videotapes to evaluate physician performance in actual medical visits has proved to be a reliable measure [20]. After completing the training the paediatricians were asked to indicate on a seven point Likert scale, with 'negative' and 'positive' marking the endpoints, how they evaluated the training, whether they thought they had learned enough, and how they assessed the expertise of the trainers. In addition, they were asked to indicate the value of the different ingredients by means of open-ended questions. For various reasons, only four trainees attended all training sessions; one trainee was absent for one halfday, four missed one whole day, and one trainee missed 2 days.

\section{[ TABLE 2 ]}

\section{Analysis of communication}

Paediatricians' verbal and nonverbal communication was measured by four independent raters directly from the video recordings using the CAMERA computer system [34]. The raters were trained in using the observation instrument and they were unaware of the study hypotheses.

\section{Verbal behaviour}

The verbal communication process was analysed using an adjusted version of the Roter Interaction Analysis System [3, 8, 9, 24]. This system distinguishes between instrumental (giving information, asking questions, and counselling) and affective (giving comfort and reassurance and showing optimism and concern) verbal utterances (Table 3). To control for potential differences in lengths of visits, clusters were divided by the total count of utterances yielding mean percentages.

\section{[ TABLE 3 ]}

\section{Nonverbal behaviour}

Patient-directed gaze, i.e. the time the paediatrician looked directly into the parent's or the child's face, was measured and adjusted for the time the paediatrician was in sight. Camera angles did not permit coding of the direction of the paediatrician's nonverbal behaviour, i.e. whether the paediatrician looked at the parent or the child.

\section{Interrator reliability}

To establish interrator reliability, all four observers coded the same 16 videotaped encounters. The overall average pair-wise Pearson correlation coefficient for physician clusters was 0.83 (range 0.700.99). The overall interrator reliability for nonverbal communication, i.e. the duration of patientdirected gaze was 0.98 .

The effects of the communication training were assessed by examining changes in the weighted mean percentages of the above mentioned communication behaviours. In addition to these specific communication behaviours, the following measures were assessed: 1) a psychosocial composite, i.e. a ratio psychosocial categories/ biomedical categories, reflecting the focus of the encounter; 2) a combination of parent's and child's conversational contribution relative to the total count of utterances; 3) patient-directed gaze, i.e. the time the paediatrician looked at the parent or the child; and 4) the length of the outpatient visit. 


\section{Statistical analysis}

Paediatricians were asked to videotape several encounters. It was, therefore, important to take into account the similarity among encounters by one paediatrician. This exploration required multilevel analysis $[5,10,23]$, a statistical method that creates the option of analysing data at the level of the paediatrician, without disregarding the variance on the patient level. Using the MLN software for multilevel analysis appropriate, first intraclass correlation coefficients were calculated to investigate whether encounters by one paediatrician had a greater degree of similarity than encounters by different paediatricians. The magnitude of the intraclass coefficients for most paediatrician communication behaviours (range 0.0-0.45) necessitated the use of multilevel analysis [9]. Two levels were explored: the lowest level refers to patient variables and the second level to paediatrician variables. It has been shown previously that paediatricians' communication style is related to the child's age and sex, and on whether paediatrician and patient were already acquainted with one another [9]. Therefore, these variables were accounted for. Additional multilevel contrast analyses were performed to test for differences within the pre- and postmeasurements between the control and the experimental group as well as within the experimental and control group between pre- and post-measurement. As a previous paper on paediatrician-parent-child communication had not examined the influence of paediatrician characteristics [9], the results on this topic will be presented in a separate section by means of regression coefficients (r).

\section{RESULTS}

\section{Trainees' evaluation of the training}

Paediatricians were generally enthusiastic about the communication training. Their mean scores were 5.5 (range 4.5-7.0) for the evaluation of the course in general, 5.3 (range 4.0-6.0) for whether they felt they learned enough, and 5.6 (range 4.0-7.0) for their assessment of the expertise of the trainers. Their answers to the open questions showed that they particularly valued the following ingredients of the training: watching themselves perform on the videotapes, role-playing, practising, receiving and giving feedback, and learning to put communication theory into practice. Paediatricians furthermore expressed their intention to become more attentive to the patients and their parents and to allow more room for patients' and parents' perception and experience of their condition. They also intended to bring more structure into the medical visits and to prepare themselves better before each visit. Before the training a lot of paediatricians felt that the training was too long. Afterwards, they all agreed that the training was too short and that they would appreciate a follow-up. They all stated that they would recommend the training to their colleagues.

\section{Paediatrician characteristics}

Before analysing training effects, the influence of paediatrician characteristics on communication was considered. Adding these characteristics to the multilevel model yielded several significant relationships. The more experienced the paediatricians were, the more they disagreed with the parent or the child $(r=0.02, \mathrm{SE}=0.01)$. In addition, an increase in the years of experience decreased patientdirected gaze by more than $2 \%(r=) 2.19, \mathrm{SE}=0.93)$ and increased parent's and child's conversational contribution $(r=0.42, \mathrm{SE}=0.21)$. An increase in paediatrician's age contributed to a decrease in parent's and child's conversational contribution $(r=) 0.45, \mathrm{SE}=0.21)$. Compared with paediatricians working on a fee-for-service basis, those with a fixed income provided more psychosocial information $(r=0.92, \mathrm{SE}=0.38)$ and more psychosocial counselling $(r=0.26, \mathrm{SE}=0.10)$. Moreover, the duration of the outpatient encounters with salaried paediatricians appeared on average to be more than 4 min longer $(r=4.68, \mathrm{SE}=1.07)$. No differences were found in the communication behaviours of female and male paediatricians.

\section{Training effects}

Tables 3 and 4 show the weighted mean percentages of paediatrician communication behaviours and composites at pre- and post-measurement. Comparisons were made between the scores of the trained paediatricians at post-measurement and the other measurements. Several significant differences emerged. At post-measurement, trained paediatricians appeared to express more agreements, to provide more medical information, and to ask more psychosocial questions. Furthermore, they gave parents and children more time to talk and looked at them more often. Trained paediatricians also 
appeared to express fewer concerns, reassurances, disagreements, orientations and medical advices and they asked less often for understanding. No effects were found on the length of the outpatient visits.

\section{[ TABLE 4 ]}

By means of contrast analysis, significant differences were found on asking psychosocial questions $\left(\chi^{2}=6.04, \mathrm{df}=2, P<0.05\right)$ and on patient-directed gaze $\left(\chi^{2}=12.04, \mathrm{df}=2, P<0.005\right)$ between the post-measurements of the control and the experimental group; trained paediatricians performed higher on both ratings. Contrast analysis also showed that at baseline, paediatricians in the control group expressed significantly more concerns than those in the experimental group $\left(\chi^{2}=9.36, \mathrm{df}=2, P<\right.$ $0.01)$. No other differences were found between the scores of the control- and the experimental group at pre- and post-measurement. Contrasting the scores of the experimental group at pre- and postmeasurement showed significant decreases in the percentages reassurances, disagreements, orientations, and medical advice, and significant increases in percentage of psychosocial questions, medical information and patient-directed gaze. Within the control group, contrast analysis of pre- and post-measurement showed significant decreases in the percentages of paediatrician expressed concerns, reassurances and medical advices. A significant increase was found between the pre- and post-measurement score on the provision of medical information by control group paediatricians.

\section{DISCUSSION}

After completing the communication training, paediatricians generally became more attentive to parents' and patients' needs. This was shown verbally by paediatricians inquiring more about how patients experienced their condition, by becoming less rejective and less dominant, and by expressing more agreements. Nonverbally this was shown by allowing patients more room to talk and by looking at the patients more often. Verbal and nonverbal communication skills have recently been identified as important tools for detecting psychosocial problems $[4,35]$ and therefore require specific attention in communication courses for health care providers. In concurrence with earlier findings $[18,37]$, paediatricians obviously can be taught to include children and parents in the conversation. The observed increase in attention to non-medical aspects did not occur at the expense of the length of the outpatient visit. This confirms the findings from recent studies in primary care [26, 27] and accords with the argumentation of Stewart et al. [31] that when a doctor has mastered a patient-centred attitude, medical visits will no longer take more time as the interaction automatically focuses on for the individual patient most relevant issues. These positive training effects are in line with the intentions paediatricians expressed immediately after completing the training.

There were, however, also a few unexpected findings that need to be clarified. At post-measurement, trained paediatricians appeared to express less concern while interacting with their patients. This may be the result of the fact that at pre-measurement, control group paediatricians expressed significantly more concerns and can therefore, with respect to that particular comparison, not be considered as a valid group of reference for the experimental group ratings. In addition, paediatricians in the control group also expressed less concerns at post-treatment. Trained paediatricians also appeared to behave in a less reassuring fashion. Patients often regard physicians' nonspecific reassurance as a way of neglecting the seriousness of their problems [6]. Expressing less reassurance can therefore not automatically be interpreted as a negative outcome of training. Control group paediatricians also became less reassuring. After the training, paediatricians expressed fewer orientations. The majority of orientations uttered by paediatricians were signs of holding track of the conversation by using separate statements like 'okay' or 'let's see'. By using such expressions paediatricians attempt to structure the interaction but only according to their own agenda [16]. Following this line of reasoning the decrease in providing medical advice can also be understood positively as a decrease in paediatrician dominance or 'doctor-centredness', or, alternatively, be meaningless as the advices expressed by control group paediatricians diminished also between pre- and post-measurement. As the control group paediatricians gave more medical information at postmeasurement, the increase in the provision of medical information in the experimental group can not only be the result of the communication training. 
Contrary to the study of Joos et al. [13], but in accordance with others [17, 25, 26, 28, 35-37], this study found several important improvements in paediatrician communication behaviours as measured by Roter Interaction Analysis System scores. Nevertheless, there were a few shortcomings in this study that may have prevented greater improvements. Due to restricted financial resources, we were unable to present our communication course to more than two groups of paediatricians. As there are a number of paediatricians waiting to take our course, we still hope to obtain additional funds. We did consider it worthwhile to report our findings on a relatively small group of paediatricians, as it might stimulate others in developing professional education programmes. Given the number of paediatricians that participated in the present study, for the moment, our findings may have to be considered preliminary. Unfortunately not every paediatrician was able to attend all training meetings. The training required a commitment of trainee time. In the future, absence may be prevented by tuning the programme of the training more to paediatricians' wishes and schedules. All paediatricians did, however, receive feedback on their communication style and brought their actual performance under discussion. In addition, the trainees were not blinded to the videotaped evaluation of their performance. Yet, former research has shown that being videotaped has no effect on physicians' communication behaviour [22]. In addition, the raters were blinded to the status of the trainees. The communication training was accredited by the Paediatric Association of the Netherlands. All certified paediatricians need to attend a certain number of accredited courses each year in order to keep their certification. This may have encouraged paediatricians to undertake the training. It is possible that paediatricians who participated in the training already valued communication skills prior to training. Nevertheless, positive training effects were found in this possibly already effectively communicating group of paediatricians.

Just recently, almost all Dutch paediatricians who formerly worked on a fee-for-service basis shifted to a fixed income. On the basis of the present findings on the relationship between reimbursement system and communication behaviours, one might expect the nature of the outpatient paediatric encounters to change in time. Encounters will probably take more time in which psychosocial issues will be discussed in more detail. So the physician reimbursement system appears to have an impact on the quality of care. This issue will be elaborated on in a separate paper.

One question that still needs to be answered is how long the effects of the present training will last, that is, how long will paediatricians continue to do what they have been trained to do? Retention of the acquired interviewing skills beyond the time of the training course will be examined when the trained paediatricians have supplied another series of videotaped outpatient encounters long after the training has been completed. The results presented in this paper show that continuing paediatric education in communication skills is worthwhile, the more so when one considers the finding that older paediatricians allow patients and their parents less room in the conversation. The results of this training will be used by the residency programme committee of the Paediatric Association of the Netherlands in defining training requirements and needs in interviewing skills and in the psychosocial aspects of paediatric practice.

\section{ACKNOWLEDGEMENTS}

The authors greatly appreciate the participation of the paediatricians and the parents who gave permission to videotape their medical visit.

\section{TABLES}

Table 1 Paediatrician and patient characteristics. $S D$ standard deviation

\begin{tabular}{|c|c|c|c|c|}
\hline Characteristics & $\begin{array}{l}\text { Experimental } \\
\text { group }(n, \%)\end{array}$ & Mean (SD) & $\begin{array}{l}\text { Control } \\
\text { group }(n, \%)\end{array}$ & $\begin{array}{l}\text { Mean } \\
\text { (SD) }\end{array}$ \\
\hline Paediatricians $(n)$ & 10 & & 11 & \\
\hline Male $(n)$ & $6(60)$ & & $6(54)$ & \\
\hline Fixed income $(n)$ & $9(90)$ & & $5(45)$ & \\
\hline Age (years) & & $45.0(7.0)$ & & $46.0(7.0)$ \\
\hline Experience (years) & & $12.0(6.0)$ & & $13.0(7.0)$ \\
\hline Patients $(n)$ & 282 & & 326 & \\
\hline Male $(n)$ & $161(57)$ & & $195(60)$ & \\
\hline First visit $(n)$ & $40(14)$ & & $49(15)$ & \\
\hline Age (years) & & $5.3(4.0)$ & & $5.3(4.0)$ \\
\hline
\end{tabular}


Dulmen, A.M. van, Holl, R.A.

Effects of continuing paediatric education in interpersonal communication skills.

European Journal of Pediatrics: 159, 2000, p. p. 489-495

Table 2 Pretest/post-test control group design; number of videotaped encounters

\begin{tabular}{llll}
\hline & T0 & Training & T1 \\
\hline Intervention group $(n=10)$ & 142 & Yes & 140 \\
Control group $(n=11)$ & 159 & No & 167 \\
\hline
\end{tabular}

Table 3 Mean percentages and standard errors of paediatrician communication behaviours at pre- and post-measurement, weighted by patient and paediatrician characteristics. $S E$ standard error
Table 4 Communication composites and visit length at pre- and post-measurement, weighted by patient and paediatrician characteristics. $S E$ standard error

\begin{tabular}{|c|c|c|c|c|}
\hline \multirow[t]{2}{*}{ Variable } & \multicolumn{2}{|c|}{ Pre-measurement } & \multicolumn{2}{|c|}{ Post-measurement } \\
\hline & $\begin{array}{l}\text { Control mean } \\
(\mathrm{SE})^{\mathrm{a}}\end{array}$ & $\begin{array}{l}\text { Experimental } \\
\text { mean }(\mathrm{SE})^{\mathrm{a}}\end{array}$ & $\begin{array}{l}\text { Control mean } \\
\text { (SE) }\end{array}$ & $\begin{array}{l}\text { Experimental } \\
\text { mean }(\mathrm{SE})^{\mathrm{a}}\end{array}$ \\
\hline \multicolumn{5}{|l|}{ Affective } \\
\hline Social behaviour & $6.35(0.87)$ & $5.52(0.91)$ & $6.95(0.87)$ & $5.42(0.91)$ \\
\hline Agreements & $7.67(0.65)$ & $6.89(0.68)$ & $7.40(0.65)$ & $7.69(0.68)^{\mathrm{b}}$ \\
\hline Paraphrases & $3.45(0.30)$ & $3.57(0.32)$ & $3.17(0.30)$ & $3.36(0.31)$ \\
\hline Reflections & $0.46(0.08)$ & $0.61(0.08)$ & $0.49(0.07)$ & $0.62(0.08)$ \\
\hline Concerns & $0.65(0.07)$ & $0.38(0.07)$ & $0.33(0.06)$ & $0.28(0.07)^{\mathrm{b}}$ \\
\hline Reassurances & $1.53(0.20)$ & $1.19(0.21)$ & $0.49(0.20)$ & $0.09(0.20)^{\mathrm{b}}$ \\
\hline Disagreements & $0.14(0.03)$ & $0.13(0.04)$ & $0.13(0.03)$ & $0.05(0.04)^{b}$ \\
\hline \multicolumn{5}{|l|}{ Instrumental } \\
\hline Orientations & $10.26(0.74)$ & $10.05(0.77)$ & $9.66(0.73)$ & $8.37(0.76)^{\mathrm{b}}$ \\
\hline Ask for clarification & $2.99(0.43)$ & $3.29(0.45)$ & $3.15(0.42)$ & $2.67(0.44)^{\mathrm{b}}$ \\
\hline Medical questions & $5.16(0.47)$ & $5.42(0.49)$ & $5.53(0.47)$ & $5.39(0.49)$ \\
\hline Psychosocial questions & $0.96(0.16)$ & $1.08(0.16)$ & $0.99(0.16)$ & $1.40(0.16)^{\mathrm{b}}$ \\
\hline Medical information & $13.96(0.98)$ & $14.56(1.03)$ & $16.47(0.97)$ & $17.73(1.03)^{\mathrm{b}}$ \\
\hline Psychosocial information & $1.45(0.41)$ & $1.46(0.33)$ & $1.41(0.41)$ & $1.40(0.33)$ \\
\hline Medical counselling & $3.83(0.31)$ & $3.55(0.33)$ & $2.61(0.31)$ & $1.83(0.33)^{b}$ \\
\hline Psychosocial counseling & $0.42(0.11)$ & $0.39(0.09)$ & $0.39(0.11)$ & $0.36(0.09)$ \\
\hline Administrative & $1.41(0.27)$ & $1.18(0.28)$ & $1.13(0.27)$ & $1.16(0.28)$ \\
\hline
\end{tabular}

${ }^{a}$ For the experimental group, pre- and post-measurements accord with the measurements before and after the training, respectively. The control group was not trained

${ }^{\mathrm{b}}$ The percentage differs significantly from the other three measurements $(P<0.05)$

\begin{tabular}{|c|c|c|c|c|}
\hline \multirow[t]{2}{*}{ Variable } & \multicolumn{2}{|c|}{ Pre-measurement } & \multicolumn{2}{|c|}{ Post-measurement } \\
\hline & $\begin{array}{l}\text { Control mean } \\
\text { (SE) }\end{array}$ & $\begin{array}{l}\text { Experimental } \\
\text { mean (SE) }\end{array}$ & $\begin{array}{l}\text { Control mean } \\
\text { (SE) }\end{array}$ & $\begin{array}{l}\text { Experimental } \\
\text { mean (SE) }\end{array}$ \\
\hline Psychosocial composite & $0.15(0.03)$ & $0.16(0.04)$ & $0.11(0.03)$ & $0.18(0.04)$ \\
\hline $\begin{array}{l}\text { Conversational } \\
\text { contribution }\end{array}$ & $40.19(0.72)$ & $41.42(0.76)$ & $40.59(0.71)$ & $42.80(0.76)^{*}$ \\
\hline Patient-directed gaze & $46.38(2.91)$ & $52.50(3.06)$ & $44.83(2.90)$ & $56.74(3.07)^{*}$ \\
\hline Visit length & $22.04(1.53)$ & $23.46(1.29)$ & $21.65(1.52)$ & $22.64(1.28)$ \\
\hline
\end{tabular}

* Significantly different from the other three measurements $(P<0.05)$

\section{REFERENCES}

1. Altmaier EM, McGuinness G, Wood P, Ross RR, Bartley J, Smith W (1990) Defining successful performance among pediatric residents. Pediatrics 85: 139:143

2. American Board of Pediatrics (1987) Teaching and evaluation of interpersonal skills and ethical decision making in pediatrics.

Pediatrics 79: 829:833

3. Bensing JM (1991) Doctor-patient communication and the quality of care. NIVEL, Utrecht

4. Bensing JM, Kerssens JJ, Pasch van der M (1995) Patient-directed gaze as a tool for discovering and handling psycho-social problems in general practice. J Nonverb Behav 19: 223: 242

5. Bryk AS, Raudenbusch SW (1992) Hierarchical linear models: applications and data management methods. Sage publications, Newbury Park

6. Buchsbaum DG (1986) Reassurance reconsidered. Soc Sci Med 23: 423:427

7. Charney $E$ (1995) The education of pediatricians for primary care: the score after two score years.

Pediatrics 95: 270:272

8. Dulmen AM van, Verhaak PFM, Bilo HJG (1997) Shifts in doctor-patient communication during a series of outpatient consultations in non-insulin-dependent diabetes mellitus. Pat Educ Couns 30: 227:237

9. Dulmen AM van (1998) Children's contribution to pediatric outpatient encounters. Pediatrics 102: 563:568

10. Goldstein H (1995) Multilevel statistical models, 2nd edn.

Halstead Press, New York 
Dulmen, A.M. van, Holl, R.A.

Effects of continuing paediatric education in interpersonal communication skills.

European Journal of Pediatrics: 159, 2000, p. p. 489-495

11. Greer SW, Styczynski LE (1990) Training pediatricians in family therapy. J Dev Behav Pediatr 11: 198:200

12. Henbest RJ, Stewart M (1990) Patient-centredness in the consultation 2: Does it really make a difference? Fam Pract 7: 28:33

13. Joos SK, Hickam DH, Gordon GH, Baker LH (1996) Effects of a physician communication intervention on patient care outcomes. J Gen Intern Med 11: 147:155

14. Kern DE, Grayson M, Barker LR et al (1989) Residency training in interviewing skills and the psychosocial domain of medical practice. J Gen Int Med 4: 421:431

15. Kurtz SM, Silverman JD (1996) The Calgary-Cambridge Referenced Observation Guides: an aid to defining the curriculum and organizing the teaching in communication training programmes. Med Educ 30: 83:89

16. Levenstein JH, McCracken EC, McWhinney IR, Stewart MA, Brown JB (1986) The patient-centred clinical method. 1. A model for the doctor-patient interaction in family medicine.

Fam Pract 3: 24:30

17. Levinson W, Roter D (1993) The effects of two continuing medical education programs on communication skills of practicing primary care physicians. J Gen Intern Med 8: 318:324

18. Lewis CC, Pantell RH, Sharp L (1991) Increasing patient knowledge, satisfaction, and involvement. Randomized trial of a communication intervention. Pediatrics 88: 351:358

19. Makoul G, Schofield T (1999) Communication teaching and assessment in medical education: and international consensus statement. Pat Educ Couns 137: 191:195

20. McCormick DP, Rassin GM, Stroup-Benham CA et al (1993) Use of videotaping to evaluate pediatric residents performance of health supervision examinations of infants. Pediatrics 92: 116:120

21. Oberklaid $F$ (1991) Mismatch between paediatric training and paediatric practice. Lancet 337: 920

22. Pringle M, Stewart-Evans C (1990) Does awareness of being video recorded affect doctors' consultation behaviour? Br J Gen Pract 40: 455:458

23. Rasbash J, Woodhouse G (1995) MLN Command Reference.

Institute of Education, University of London, London

24. Roter D (1989) The Roter method of interaction process analysis. Johns Hopkins University, Baltimore

25. Roter DL, Cole KA, Kern DE, Barker LR, Grayson M (1990) An evaluation of residency training in interviewing skills and the psychosocial domain of medical practice. J Gen Intern Med 5: 347:354

26. Roter DL, Hall JA, Kern DE, Barker LR, Cole KA, Roca RP (1995) Improving physicians' interviewing skills and reducing patients' emotional distress. A randomized clinical trial. Arch Intern Med 155: 1877:1884

27. Roter DL, Stewart M, Putnam SM, Lipkin M, Stiles W, Inui TS (1997) Communication patterns of primary care physicians.

JAMA 277: 350:356

28. Roter D, Rosenbaum J, de Negri B, Renaud D, DiPrete-Brown L, Hernandez O (1998) The effects of a continuing medical education programme in interpersonal communication skills on doctor practice and patient satisfaction in Trinidad and Tobago. Med Educ 32: 181:189

29. Scheidt PC, Lazoritz S, Ebbeling WL, Figelman AR, Moessner HF, Singer JE (1986) Evaluation of system providing feedback to students on videotaped patient encounters. J Med Educ 61: 585:590

30. Simpson M, Buckman R, StewartMet al (1991) Doctor-patient communication: the Toronto consensus statement. BMJ 303: 1385:1387

31. Stewart M, Brown JB, Weston WW (1989) Patient-centred interviewing. Part III: five provocative questions. Can Fam Physician 35: 159:161

32. Towle A (1998) Changes in health care and continuing medical education for the 21st century. BMJ 316: 301:304

33. Visser HKA (1993) Paediatrics in the Netherlands: challenges for today and tomorrow. Arch Dis Child 69: 251:255

34. Vlugt van der MJ, Kruk MR, Erp van AMM, Geuze RH (1992) CAMERA: a system for fast and reliable acquisition of multiple ethological records. Beh Res Meth Instrum Comput 2: 147:149

35. Wissow LS, Roter D (1994) Toward effective discussion of discipline and corporal punishment during primary care visits: findings from studies of doctor-patient interaction. Pediatrics 94: 587:593

36. Wissow LS, Roter DL, Wilson MEH (1994) Pediatrician interview style and mothers' disclosure of psychsocial issues.

Pediatrics 93: 289:295

37. Wissow LS, Roter D, Bauman LJ, Crain E, Kercsmar C, Weiss K, Mitchell H, Mohr B (1998)

Patient-provider communication during the emergency department care of children with asthma. Med Care 36: 1439:1450 